\title{
Saga of Mcl-1: regulation from transcription to degradation
}

\author{
Viacheslav V. Senichkin ${ }^{1}$ - Alena Y. Streletskaia ${ }^{1}$ Anna S. Gorbunova ${ }^{1} \cdot$ Boris $_{\text {Zhivotovsky }}{ }^{1,2} \cdot$ Gelina S. Kopeina $^{1}$
}

Received: 13 November 2019 / Revised: 5 December 2019 / Accepted: 13 December 2019 / Published online: 6 January 2020

(c) The Author(s), under exclusive licence to ADMC Associazione Differenziamento e Morte Cellulare 2020

\begin{abstract}
The members of the Bcl-2 family are the central regulators of various cell death modalities. Some of these proteins contribute to apoptosis, while others counteract this type of programmed cell death, thus balancing cell demise and survival. A disruption of this balance leads to the development of various diseases, including cancer. Therefore, understanding the mechanisms that underlie the regulation of proteins of the Bcl-2 family is of great importance for biomedical research. Among the members of the Bcl-2 family, antiapoptotic protein Mcl-1 is characterized by a short half-life, which renders this protein highly sensitive to changes in its synthesis or degradation. Hence, the regulation of Mcl-1 is of particular scientific interest, and the study of Mcl-1 modulators could aid in the understanding of the mechanisms of disease development and the ways of their treatment. Here, we summarize the present knowledge regarding the regulation of Mcl-1, from transcription to degradation, focusing on aspects that have not yet been described in detail.
\end{abstract}

\section{Facts}

- $M C L 1$ is the first antiapoptotic gene for which homology to $B C L 2$ was reported.

- Mcl-1 plays a significant role in the inhibition of apoptosis and demonstrates oncogenic properties.

- Mcl-1 is a short-lived protein, which renders it highly sensitive to changes in its synthesis or degradation.

- Targeting regulatory circuits that control Mcl-1 level could provide a possible therapeutic intervention for cancer treatment.

\section{Open questions}

- What mechanisms are most common for Mcl-1 dysregulation during tumor development?

- Is the understanding of the mechanisms of Mcl-1 regulation relevant to comprehend the pathophysiology of non-cancer disorders?

\section{Edited by S. Kaufmann}

Boris Zhivotovsky

Boris.Zhivotovsky@ki.se

$\bowtie$ Gelina S. Kopeina

lirroster@gmail.com
- Can regulation of Mcl-1 posttranslational modifications be exploited as a therapeutic strategy to combat cancer?

- How the development of next-generation sequencing technologies should help in the understanding of mechanisms relevant to the dysregulation of Mcl-1 in patients?

\section{Introduction}

In 1993, four genes with a high level of homology were cloned: MCL1 [1], BCL2Al [2] (encoding for A1 or Bfl-1), $B C L 2 L 1$ [3] (encoding for Bcl-xL and Bcl-xS), and $B A X$ [4]. All shared sequence similarity with $B C L 2$, an oncogene that promotes haemopoietic cell survival [5]. Initial experiments demonstrated the opposite roles of the two products of the $B C L 2 L 1$ gene in the regulation of cell death: Bcl-xL served as an inhibitor of apoptotic cell death, whereas a smaller Bcl-xS countered antiapoptotic activity [3]. Next, Bax was discovered as a Bcl-2 binding partner, and its overexpression was shown to promote apoptosis [4]. These data pointed to the fact that there was a family of

1 Faculty of Medicine, MV Lomonosov Moscow State University, Moscow, Russia

2 Institute of Environmental Medicine, Karolinska Institutet, Stockholm, Sweden 
Bcl-2-like proteins that positively or negatively regulated apoptotic cell death.

MCL1 is the first gene for which homology to BCL2 was reported. It was isolated from the ML-1 human myeloid leukemia cell line and accordingly named MCLI (myeloid cell leukemia-1). In initial work, Kozopas et al. proposed that the Mcl-1 protein may regulate cell survival [1]. This assumption was later confirmed in numerous studies.

Today, there is no doubt regarding the role of Mcl-1 in the inhibition of apoptosis, as well as the resulting oncogenic properties. A thorough study of the Bcl-2 family was translated into the development of small-molecule inhibitors of its antiapoptotic members, including Mcl-1, and these compounds are now being evaluated in clinical trials [6]. The regulation of apoptosis by members of the Bcl-2 family, as well as the recent advances in targeting various $\mathrm{Bcl}-2$ family proteins, are reviewed elsewhere [6-9].

Meanwhile, the regulation of Mcl-1 is also actively studied, and numerous reviews cover this aspect of Mcl-1 biology [10-14]. As more and more data are accumulated on this issue, systematic analysis is needed to update current understanding of Mcl-1 regulation. Here, we attempted to summarize the data concerning the regulation of Mcl-1 at the transcriptional, translational, and posttranslational levels, giving examples of how these mechanisms could be involved in the modulation of cancer cell survival and how to utilize them for precision medicine.

\section{Mcl-1: functions, structure, and biological significance}

Proapoptotic and antiapoptotic members of the Bcl-2 family act through mutual inhibition, controlling permeabilization of the outer mitochondrial membrane, and the escape of various proapoptotic factors into the cytosol [15]. Once such proapoptotic factors invade the cytoplasm, the apoptotic program will be initiated [16].

All antiapoptotic members of the Bcl-2 family have a hydrophobic groove in their structure. This cleft is termed "BH3-binding groove" due to the ability of binding exposed BH3-domains, which represent the main structural features of proapoptotic Bcl-2 family members. In brief, the interactions between $\mathrm{BH} 3$-binding grooves and $\mathrm{BH} 3$-domains underlie the mutual inhibition of the two subsets of Bcl-2 family members [15]. Based on this knowledge, small molecule compounds that imitate BH3-domains were developed to target antiapoptotic Bcl-2 family proteins. According to the mechanism of action, these agents have been named "BH3-mimetics" [17]. Today, BH3-mimetics are under active clinical trials, and a specific inhibitor of Bcl-2, venetoclax, has been approved by the Food and Drug Administration and the
European Medicines Agency for clinical use. As for Mcl-1, four BH3-mimetics to this protein, S64315, AMG-176, AMG-397, and AZD-5991, have entered clinical evaluation in patients with hematological malignancies, either alone or in combination with venetoclax (NCT02979366, NCT 02992483, NCT03672695, NCT02675452, NCT03797261, NCT03465540, and NCT03218683). Nowadays, BH3mimetics represent the most promising tool for the inhibition of Bcl-2 family antiapoptotic proteins, and the approval of Mcl-1-specific inhibitors is eagerly awaited.

Although Mcl-1 possesses a structure similar to that of other antiapoptotic Bcl-2 family proteins, its size is much larger since Mcl-1 contains an extended $\mathrm{N}$-terminal regulatory domain. One of the most important features of this region is the abundance of proline $[\mathrm{P}]$, glutamic acid $[\mathrm{E}]$, serine [S], and threonine [T] residues [11]. Commonly, PEST sequences serve as signals for rapid protein degradation [18]. In line with this concept, Mcl-1 is characterized by a high turnover rate and a short half-life (usually $<1 \mathrm{~h}$ ) [19]. This feature makes Mcl-1 extremely sensitive to perturbations in its synthesis and/or degradation.

It should be mentioned that for Mcl-1 additional splicing variants with proapoptotic activity have been described $[20,21]$. Here, however, we focus on only the most abundant antiapoptotic isoform of Mcl-1.

Like other antiapoptotic proteins of the Bcl-2 family, Mcl-1 plays an important role in the survival of various types of normal cells, including hematocytes [22], neurons [23], cardiomyocytes [24], and others. Like other antiapoptotic proteins of the Bcl-2 family, Mcl-1 is also often abused by cancer cells to evade apoptosis. The expression of Mcl-1 in tumor cells was found in a high proportion of patients with acute myeloid leukemia (AML) [25], hepatocellular carcinoma [26], non-small cell lung cancer [27], breast cancer [28], and other malignancies [29]. Mcl-1 is associated with resistance of tumor cells to various anticancer agents, [17, 30-32] while Mcl-1 dependence serves as a predictor of worse response to $\mathrm{BH} 3$-mimetic venetoclax in AML patients [33]. Moreover, Mcl-1 upregulation was found at the time of relapse in chemotherapy-treated leukemia patients, thus highlighting the role of Mcl-1 in tumor biology [34]. Hence, Mcl-1 is both an essential regulator of survival in normal cells and a promising target for cancer therapy.

\section{Regulation of Mcl-1}

Numerous modulators finely regulate Mcl-1 level by providing rapid protein-level changes in response to internal and external signals. MCL1 gene expression is controlled at transcriptional, posttranscriptional, and translational levels. Moreover, various posttranslational modifications 
determine the stability and functional activity of Mcl-1. Dysregulation of Mcl-1 may result in various pathological processes, including carcinogenesis. Thereby, understanding the molecular mechanisms that underlie the regulation of Mcl-1 is of great therapeutic significance.

\section{Transcriptional control of $\mathrm{Mcl}-1$}

Different cytokines, growth factors, and other extracellular and intracellular stimuli, including IL- 6 and IFN- $\alpha$ in multiple myeloma cells [35], hepatocyte growth factor in primary human hepatocytes [36], epidermal growth factor (EGF) in esophageal carcinoma [37] and breast cancer cells [38], can control MCL1 transcription. MCL1 is transcriptionally modulated in response to different cellular stresses, such as microtubule disruption [39], ER stress [40], and hypoxia [41]. Importantly, the dysregulation of MCL1 transcription could be utilized by cancer cells to develop apoptosis resistance. In general, transcriptional regulation represents an important node in the complex regulation of Mcl-1. Table 1 summarizes the data regarding transcriptional factors, which were found to bind to the promoter region of human $M C L 1$.

It is noteworthy to mention that several studies focused on the binding of transcription factors to the promoter of the mouse Mcll, but not of its human counterpart. Although both promoters have a certain degree of homology, the binding of transcription factors to the mouse Mcll promoter, apparently, should not always be extrapolated to human MCL1. Thus, activating transcription factor 5 (ATF5) was shown to be a regulator of Mcl-1 in mouse neuroblastoma cells [42]. However, no significant correlation between Mcl-1 and ATF5 levels in patient samples was observed [42], and further study failed to prove the role of ATF5 in the regulation of Mcl-1 transcription in human cells [43]. Whether ATF5 can transcriptionally activate human MCL1 remains to be elucidated. In general, transcription factors found to regulate non-human Mcll should be confirmed with the human gene to avoid possible misinterpretation.

\section{Posttranscriptional control of $\mathrm{Mcl}-1$}

Posttranscriptional control of Mcl-1 includes pre-mRNA splicing and regulation of mRNA levels. In addition to the Mcl-1 protein, the corresponding mRNA has a very short half-life $(\sim 2-3 \mathrm{~h})$ [39]. The turnover of Mcl-1 mRNA is modified by several RNA-binding proteins and also by multiple regulatory RNAs. The RNA-binding proteins and microRNAs (miRNAs) participating in Mcl-1 posttranscriptional control, as well as splicing regulators, were recently reviewed in detail [44]. Hence, these aspects are not covered here.
In addition to miRNAs, several long non-coding RNAs (lncRNAs) were found to modulate Mcl-1 mRNA stability. LncRNAs represent a class of RNA molecules more than 200 nucleotides in length and devoid of protein-coding ability. LncRNAs are implicated in the regulation of gene expression by diverse mechanisms [45], one of which is acting as decoys in order to prevent the binding of miRNAs to their targets. Since this mechanism of regulation could be readily assessed via bioinformatics analysis of complementary sequences, most of the described lncRNAs that modulate Mcl-1 mRNA stability regulate its levels in this way. Table 2 contains information about lncRNAs that have been found to control Mcl-1 expression.

\section{Translational control of $\mathrm{Mcl}-1$}

As a short-lived protein, Mcl-1 is highly sensitive to alterations in the translational activity of a cell. Hence, the modulation of eukaryotic initiation factors, which are important regulators of translation, controls Mcl-1 levels. Many cellular stresses converge on the phosphorylation of eIF2 at Ser51 in order to block general translation. ER stress, UVC, elevated osmotic pressure, and arsenite treatment decrease Mcl-1 levels through eIF2-mediated translational suppression [46]. Perhaps a more selective way to control Mcl-1 synthesis is the regulation of cap-dependent translation (CDT), a common translational mechanism controlled by the eIF4F protein complex, the assembly of which is positively regulated by the mammalian target of rapamycin complex 1 (mTORC1). eIF4F availability differently influences the translation of various mRNAs. Socalled "strong mRNAs" (e.g., $\beta$-actin) are minimally affected by alterations in eIF4F complex formation, whereas "weak mRNAs" strongly depend on eIF4F availability [47]. There are strong evidence that Mcl-1 mRNA exemplifies "weak mRNA" [48-50]. The 5'UTR of Mcl-1 mRNA presumably possesses a substantial secondary structure, which is one of the possible reasons for the "weakness" of Mcl-1 mRNA [50]. Of note, in numerous studies, mTORC1 was reported to positively regulate Mcl-1 synthesis through regulation of CDT [48], while AMP-activated protein kinase (AMPK) led to the opposite effect $[49,51]$. Thus, the nutrient and energy sensors of the cell, mTORC1 and AMPK, respectively, are important regulators of the synthesis of short-lived Mcl-1.

\section{Phosphorylation of Mcl-1}

Different types of posttranslational modifications ensure a rapid response to cellular needs. Phosphorylation is the most abundant type of posttranslational modification, which tightly regulates the activity, localization, protein-protein interactions, and the stability of individual proteins [52, 53]. 


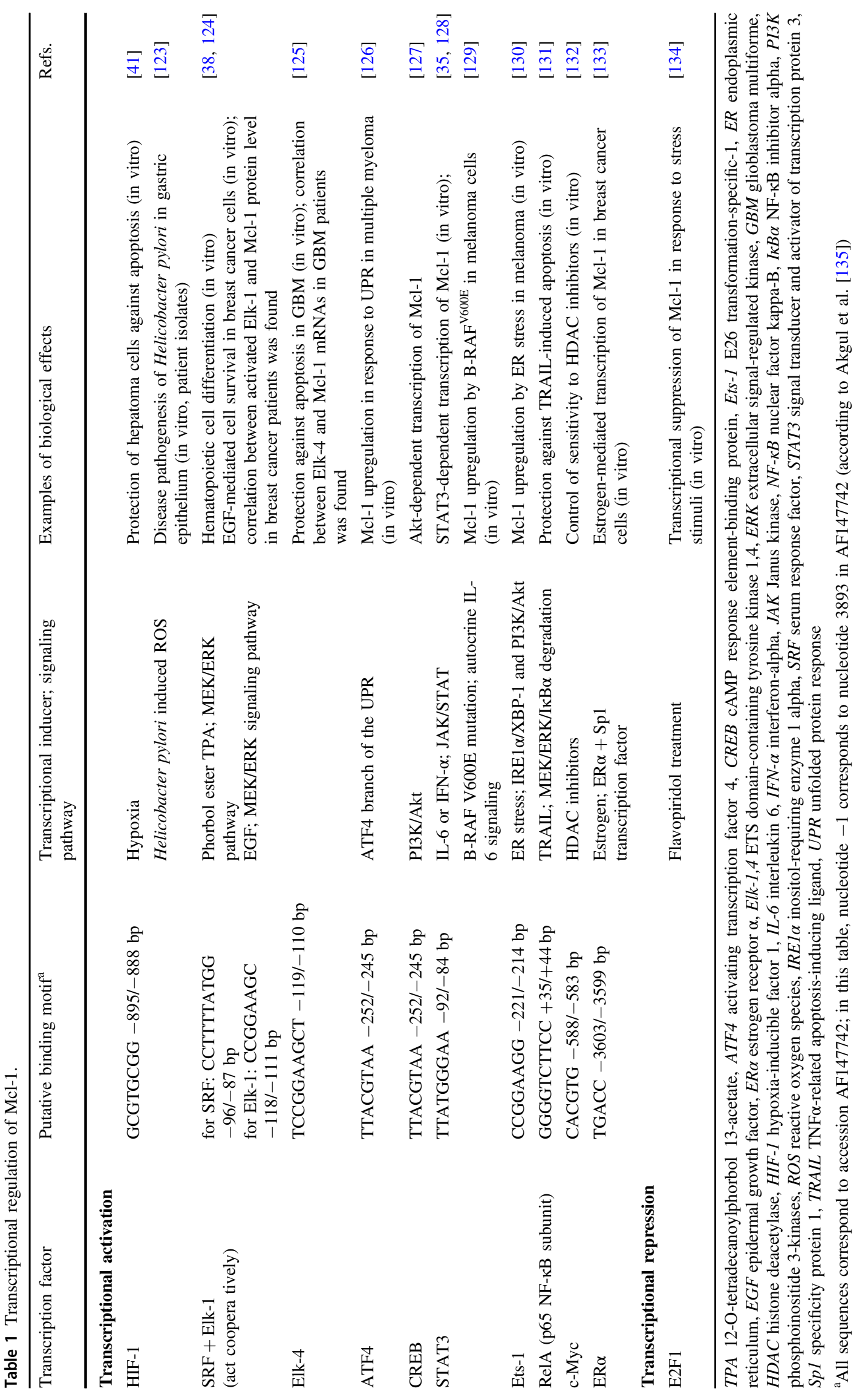


Table 2 Regulation of Mcl-1 expression by lncRNAs.

\begin{tabular}{|c|c|c|c|c|}
\hline LncRNA & Influence on Mcl-1 & Mechanism of action & Possible disease link & Refs. \\
\hline & & $\begin{array}{l}\text { Targeting miRNA, which negatively regulates Mcl- } \\
1 \text {; type of regulation }\end{array}$ & & \\
\hline \multirow[t]{3}{*}{ MALAT1 } & Positive & miR-363-3p; sponging & Gallbladder carcinoma & [136] \\
\hline & & miR-101-3p; sponging & Lung adenocarcinoma & [137] \\
\hline & & $\begin{array}{l}\mathrm{miR}-29 \mathrm{a} / \mathrm{b}-1 \text {; increased } \mathrm{H} 3 \mathrm{~K} 27 \mathrm{me} 3 \text { modification at } \\
\text { the promoter region of miR-29a/b- } 1\end{array}$ & Multiple myeloma & [138] \\
\hline ANRIL & Positive & miR-127; sponging & Ischemic stroke & [139] \\
\hline circHIPK3 & Positive & miR-193a-3p; sponging & Prostate cancer & [140] \\
\hline H19 & Positive & miR-29b-3p; sponging & Multiple myeloma & [141] \\
\hline HULC & Positive & miR-124; sponging & Atherosclerosis & [142] \\
\hline \multirow[t]{2}{*}{ LINC00152 } & Positive & miR-193a-3p; sponging & Gastric cancer & [143] \\
\hline & & miR-125b; sponging & Ovarian cancer & [144] \\
\hline MYOSLID & Positive & miR-29c-3p; sponging & Gastric cancer & [145] \\
\hline PMS2L2 & Positive & miR-203; sponging & Osteoarthritis & [146] \\
\hline \multirow[t]{2}{*}{ SNHG12 } & Positive & miR-320a; downregulation & Osteosarcoma & [147] \\
\hline & & Other mechanisms & & \\
\hline circOMA1 & Positive & $\begin{array}{l}\text { Sponges miR-145-5p, which targets mRNA of TPT1. } \\
\text { The latter was shown to increase the stability of } \\
\text { Mcl-1 protein [19] }\end{array}$ & Nonfunctioning pituitary adenoma & {$[148]$} \\
\hline PVT1 & Positive & $\begin{array}{l}\text { Increases Mcl-1 mRNA stability by an unknown } \\
\text { mechanism }\end{array}$ & Renal cell carcinoma & [149] \\
\hline Linc-ITGB1 & Negative & Unknown & Clear cell renal cell carcinoma & {$[150]$} \\
\hline
\end{tabular}

Mcl-1 possesses many potential phosphorylation sites due to the presence of the large regulatory region with two "weak" and two "strong" PEST motifs [11]. Phosphorylation of Mcl-1 is a degradation predictor, although it may also stabilize Mcl-1 and/or control its antiapoptotic activity (i.e., modulate interactions with proapoptotic Bcl-2 family members). Moreover, phosphorylation of one and the same residue can lead to different consequences depending on the phosphorylation status of the other residues.

Phosphorylation of Thr163 is a good example of this intricate regulation. Extracellular signal-regulated kinase (ERK)-mediated phosphorylation of Thr163 (probably in conjunction with phosphorylation of Thr92) results in the increased stability and antiapoptotic activity of Mcl-1 [54, 55]. However, phosphorylation of Thr163 together with Thr92, Ser121, and Ser159 (and, possibly, Ser155) targets Mcl-1 for ubiquitination and subsequent proteasomal degradation [56-59]. In numerous studies, glycogen synthase kinase 3 (GSK-3) was suggested to be a crucial kinase responsible for Ser121, Ser155, Ser159, and Thr163 phosphorylation [56-58]. Triple Mcl-1 mutant S155A + S159A $+\mathrm{T} 163 \mathrm{~A}$ demonstrates enhanced stability that rescues breast cancer cell line MCF-7 from constitutively active GSK-3 [58]. Even substitution of single residue Ser159 with alanine increased Mcl-1 stability upon GSK-3 activation [57]. In addition, GSK-3-mediated phosphorylation seems to define Mcl-1 antiapoptotic activity independently of proteasomal degradation. In a recent study, histone deacetylase (HDAC) inhibitors did not cause Mcl-1 degradation, despite GSK-3 $\beta$-dependent phosphorylation of Mcl-1. Nevertheless, GSK-3 $\beta$ activity led to apoptosis, which could be due to the decreased affinity of phosphorylated Mcl-1 to its proapoptotic partners [60]. Intriguingly, during mitotic arrest other kinases [p38 MAPK, JNK1, and casein kinase II (CKII)] are involved in phosphorylation of Mcl-1 at degradation-associated residues, whereas GSK-3 is dispensable in this process in arrested cells. Hence, different kinases can phosphorylate the same residues of Mcl-1 in a context-dependent manner [59].

Thr92 phosphorylation may also lead to different outcomes. As noted above, ERK-mediated phosphorylation at Thr92 and Thr163 was shown to stabilize Mcl-1 [55]. Alternatively, Thr92 phosphorylation serves as a key step in the degradation of Mcl-1 during mitotic arrest. The latter modification is conducted by cyclin-dependent kinase 1 (CDK1) complexed with cyclin B after treatment with microtubule damaging agents (e.g., nocodazole and taxol). The T92A mutation enhances Mcl-1 stability and rendered cells more resistant to apoptosis during prolonged mitotic arrest [61]. Phosphorylation of Thr92 by CDK1 blocks the association of $\mathrm{Mcl}-1$ with protein phosphatase 2A (PP2A) and precedes phosphorylation of Ser121, Ser159, and Thr163. Hence, it was proposed that phosphorylation of Thr92 by CDK1 primes Mcl-1 for subsequent 
phosphorylation and degradation by reducing PP2A activity towards Mcl-1 [59].

Intriguingly, recent research has challenged previous data concerning the phosphorylation and stability of Mcl-1 during mitotic arrest. In HeLa cells, the "9A mutant" of Mcl-1, bearing substitutions to alanine in nine phosphorylation sites (i.e., in all known phosphorylation sites, except Ser155), was analyzed. This mutant retained antiapoptotic activity, underwent phosphorylation under mitotic arrest, and degraded as fast as wild-type Mcl-1. Although Ser155 could be responsible for Mcl-1 phosphorylation, neither the priming role of Thr92 nor phosphorylation at multiple sites were required for degradation of Mcl-1 [62]. These results show that our understanding of $\mathrm{Mcl}-1$ regulation via phosphorylation is still incomplete.

Another residue, Ser64, was also phosphorylated during the G2/M phase of the cell cycle [61, 63]. Such modification had no apparent effect on Mcl-1 half-life, as was revealed using phosphonegative (S64A) and phosphomimic (S64E) mutants. However, the S64E mutant of Mcl-1 demonstrated the enhanced affinity to Bak, Bim, and Noxa [63]. Noxa was reported to promote Mcl-1 phosphorylation at Ser64 and Thr70 by checkpoint kinase 2 (Chk2), which subsequently led to the proteasomal degradation of Mcl-1 [64].

In total, at least the following 10 residues of $\mathrm{Mcl}-1$ may undergo phosphorylation: Ser64 [63], Thr68 [62], Thr70 [64], Thr92 [55], Ser121 [65], Ser155 [58], Thr156 [62], Ser159 [57], Ser162 [62], and Thr163 [65]. Nevertheless, most of these sites are not characterized well enough to create a holistic picture of the regulation of Mcl-1 by phosphorylation.

\section{Ubiquitination and degradation of Mcl-1}

The ability of Mcl-1 to protect cells from apoptosis is controlled by modulation of the Mcl-1 level, rather than by changing its activity. The proteasomal machinery is crucial for the continuous turnover of Mcl-1 and its degradation in response to different stimuli $[13,66]$. As is well acknowledged, K48-linked polyubiquitin chains bound to lysine residues of target proteins serve as signals for proteasomal degradation [67]. Intriguingly, Mcl-1 is able to undergo proteasomal cleavage even in a cell-free system, and the $\mathrm{Mcl}-1^{\mathrm{K} \rightarrow \mathrm{R}}$ mutant (in which all lysines were mutated to arginines) could be degraded as fast as the wild-type protein [68]. Apparently, as a partially intrinsically disordered protein, Mcl-1 undergoes proteasomal degradation by the $20 \mathrm{~S}$ proteasomes independently of ubiquitin tagging [69]. Nevertheless, numerous studies have demonstrated the crucial role of ubiquitination in the regulation of Mcl-1 turnover (Fig. 1).

Multiple ubiquitin ligases and deubiquitinases orchestrate ubiquitination and the subsequent proteasomal degradation of Mcl-1. Mule (Mcl-1 ubiquitin ligase E3, also known as ARF-BP1) was the first identified Mcl-1 ubiquitin ligase. It contains the $\mathrm{BH} 3$-domain, which interacts with the $\mathrm{BH} 3$-binding groove of Mcl-1, but not with the grooves of Bcl-2 or Bcl-xL [70, 71]. Mule, thereby, can also compete for the binding of $\mathrm{BH} 3$-only proteins to $\mathrm{Mcl}-1$, or vice versa. In particular, the BH3-motif of Bim is able to displace Mule from interacting with Mcl-1, resulting in increased Mcl-1 levels [71]. Instead, Noxa favors the interaction between Mcl-1 and Mule, while abrogating binding with deubiquitinase USP9X (see below) [72]. Mule, therefore, appears to be involved in Noxa-mediated degradation of Mcl-1. Consistently, despite amplified Noxa expression, Mule-deficient primary mouse B cells demonstrate impaired degradation of Mcl-1 after etoposide treatment [73]. Mule may act as a tumor suppressor, while the increased Mcl-1 level in Mule-deficient tumors was shown to protect cells from apoptosis [74].

Membrane-associated RING-CH protein 5 (MARCH5), which localizes to the outer membrane of the mitochondria (OMM) and maintains mitochondrial homeostasis, represents another possible ubiquitin ligase for Mcl-1. Knockdown of MARCH5 reduces ubiquitination and degradation of Mcl-1 [75, 76]. However, it is not yet clear whether MARCH5 directly ubiquitinates Mcl-1. Surprisingly, despite the increased Mcl-1 levels, MARCH5 knockdown sensitized different cancer cell lines to ABT-737 (BH3mimetic to $\mathrm{Bcl}-2$ and $\mathrm{Bcl}-\mathrm{xL}$ ) treatment. MARCH5 promotes the degradation of Mcl-1 in a Noxa-dependent manner. In MARCH5-silenced cancer cells, knockdown of Noxa abolished both the accumulation of Mcl-1 and the sensitization to ABT-737 [75]. Thus, upon MARCH5 knockdown, the effect of Noxa stabilization might exceed that of Mcl-1.

The ubiquitin ligase Parkin directly ubiquitinates Mcl-1. Normally, the PTEN-induced kinase 1 (PINK1)/Parkin pathway promotes the turnover of moderately depolarized mitochondria, without inducing apoptosis. However, pronounced mitochondrial depolarization [which could take place in response to valinomycin treatment or prolonged exposure to carbonyl cyanide m-chlorophenyl hydrazone (CCCP)] results in Parkin-dependent ubiquitination of Mcl1, its degradation, and concomitant apoptosis [77, 78]. Thereby, Mcl-1 may serve as a mediator between mitochondrial depolarization and apoptosis.

Several other ubiquitin ligases of Mcl-1 $\left(\mathrm{SCF}^{\beta-\mathrm{TrCP}}\right.$, $\mathrm{SCF}^{\mathrm{FBW}}$, TRIM17) promote Mcl-1 ubiquitination in a phosphorylation-dependent manner. SCF (Skp1, Cul1, F-box-protein) is a multicomponent E3 ubiquitin ligase complex, which contains interchangeable F-box proteins for substrate recognition. Three different F-box proteins, FBW7 [56, 59], $\beta$-TrCP [58], and FBXO4 [79], were reported to mediate ubiquitination of Mcl-1 by SCF. Mcl-1 contains 


\section{a Phosphorylation of $\mathrm{Mcl}-1$}

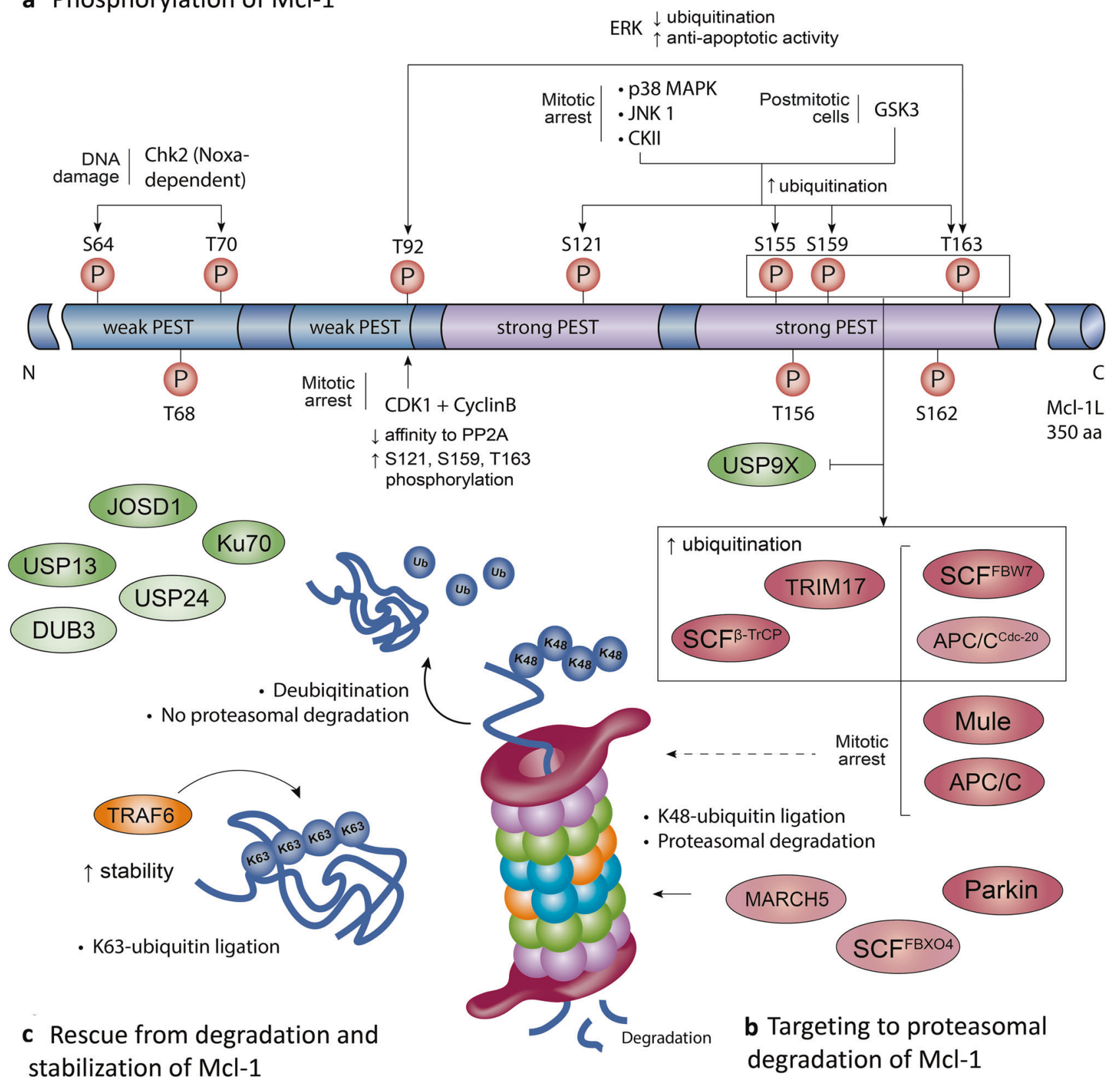

Fig. 1 Phosphorylation, ubiquitination, and deubiquitination of Mcl-1. a A distinctive feature of Mcl-1 is the presence of two weak and two strong PEST motifs in its $\mathrm{N}$-terminal region. PEST motifs are typical for proteins with relatively short half-lives, and they contain many sites of phosphorylation. Depending on the modified sites, Mcl-1 phosphorylation can lead to different effects, such as changes in Mcl-1 affinity to the binding partner, stabilization, or destabilization. For instance, phosphorylation of multiple residues in Mcl-1 degron motifs 116-125 and 154-163 targets the protein for ubiquitination and subsequent proteasomal degradation. b Several ubiquitin ligases and deubiquitinating enzymes were described as regulators of Mcl-1 degradation. Ubiquitin ligases that form K48-linked ubiquitin chains target Mcl-1 for proteasomal degradation. Some of them (SCF ${ }^{\beta-\operatorname{TrCP}}, \mathrm{SCF}^{\mathrm{FBW}}$, TRIM17, and $\left.\mathrm{APC} / \mathrm{C}^{\mathrm{Cdc} 20}\right)$ ubiquitinate $\mathrm{Mcl}-1$ in a phosphorylation-dependent manner. $\mathrm{SCF}^{\mathrm{FBW}}, \mathrm{APC} / \mathrm{C}$, and Mule were proposed to play roles during mitotic arrest. However, a recent study suggests that APC/C is a key ubiquitin ligase of Mcl-1 during mitotic arrest, while $\mathrm{SCF}^{\mathrm{FBW} 7}$ and Mule are not (see Fig. 2). c The ubiquitin ligase TRAF6 mediates K63-linked polyubiquitination and thus stabilizes Mcl-1. Deubiquitinating enzymes USP9X, USP13, USP24, DUB3, JOSD1, and Ku70 "reverse" Mcl-1 K48-linked ubiquitination and prevent its proteasomal degradation. To our knowledge, there is no data (using an in vitro enzyme activity assay) of the direct regulation of Mcl-1 by deubiquitinating peptidases USP24 and DUB3 and ubiquitin ligases MARCH5, APC/C $\mathrm{C}^{\mathrm{Cdc} 20}$, and $\mathrm{FBXO} 4$ (depicted in pale colors), which allows for the possibility of indirect regulation of Mcl-1 by these enzymes. S serine, T threonine, Ub ubiquitin, K48 ubiquitination with lysine 48 linked ubiquitin, K63 ubiquitination with lysine 63 linked ubiquitin, Chk2 checkpoint kinase 2, ERK extracellular signal-regulated kinase, p38 MAPK p38 mitogen-activated protein kinase, JNK1 c-Jun Nterminal kinase 1, CKII casein kinase II, GSK3 glycogen synthase kinase 3, CDK1 cyclin-dependent kinase 1, PP2A protein phosphatase $2 \mathrm{~A}, \mathrm{APC}$ anaphase-promoting complex, $\mathrm{APC} / \mathrm{C}^{\mathrm{Cdc}-20} \mathrm{APC}$ complexed with the celldivision cycle protein 20, Mule Mcl-1 ubiquitin ligase E3, MARCH5 membrane-associated RING-CH protein 5. 
two degron motifs for interaction with FBW7 (residues 116-125 and 154-163) and one degron motif for binding to $\beta$ - TrCP (residues 157-162) [59]. Phosphorylation of Ser121, Ser159, and Thr163 (e.g., by GSK-3) in the corresponding degrons of Mcl-1 is an essential step for the interaction with $\mathrm{SCF}^{\beta-\mathrm{TrCP}}$ and $\mathrm{SCF}^{\mathrm{FBW}}$. Consequently, FBW7 and $\beta$-TrCP are important participants of GSK-3mediated degradation of Mcl-1 [56, 58], and they can act in a redundant manner [80]. A recent study demonstrated that FBW7 may act in a context-dependent manner since the downregulation of FBW7 in cholangiocarcinoma cells affects Mcl-1 degradation in cisplatin-treated cells, but not in untreated cells [81]. Ubiquitin ligase TRIM17 was shown to ubiquitinate Mcl-1 in primary mouse cerebellar granule neurons after phosphorylation by GSK-3, and this resulted in neuronal apoptosis [82]. Recently, $\mathrm{SCF}^{\mathrm{FBXO} 4}$ was proposed to ubiquitinate Mcl-1. However, it is not clear whether FBXO4 serves as an adapter for phosphorylated Mcl-1, and the precise mechanisms of FBXO4-mediated Mcl-1 ubiquitination also remain to be elucidated [79].

A separate issue is the degradation of Mcl-1 during prolonged mitotic arrest, which occurs in response to chromosome segregation defects, e.g., after the treatment with microtubule poisons. Phosphorylation-dependent Mcl1 degradation seems to be a decisive factor in the separation of mitotic arrest and apoptosis [61]. Previously, APC/C $\mathrm{C}^{\mathrm{Cdc20}}$ (APC/C complexed with substrate recognition adapter Cdc20) [61], Mule [83], and $\mathrm{SCF}^{\mathrm{FBW} 7}$ were proposed as ubiquitin ligase systems responsible for ubiquitination of Mcl-1 during mitotic arrest [59]. At the same time, in another report these ubiquitin ligases were dispensable for Mcl-1 degradation in arrested cells [84]. This paradox could arise from the false-positive results in the initial experiments: decreased degradation of Mcl-1 after silencing Mule, FBW7, and Cdc20 might be detected in cells that slipped out of mitosis and not in arrested ones. Nevertheless, recently, using live-cell imaging, APC/C (independently of its activator Cdc20) was claimed to direct Mcl-1 degradation during mitotic arrest [85]. Live-cell imaging might be used in future studies to address possible roles of other ubiquitin ligases in the degradation of Mcl-1 during mitotic arrest in various cell lines. An understanding of such mechanisms could be useful for improving strategies to eliminate cancer cells with antimitotic drugs [85, 86] (Fig. 2).

Several ubiquitin ligases tag their substrates with K63linked polyubiquitin chains, which serve as nondegradative signals in various intracellular processes. TRAF6 is a wellknown K63 ubiquitin ligase, which, among other substrates, ubiquitinates Mcl-1 [87, 88]. Such modification stabilizes Mcl-1 by preventing its interaction with the 20S-proteasome (allegedly, owing to the steric hindrance). Intriguingly, four

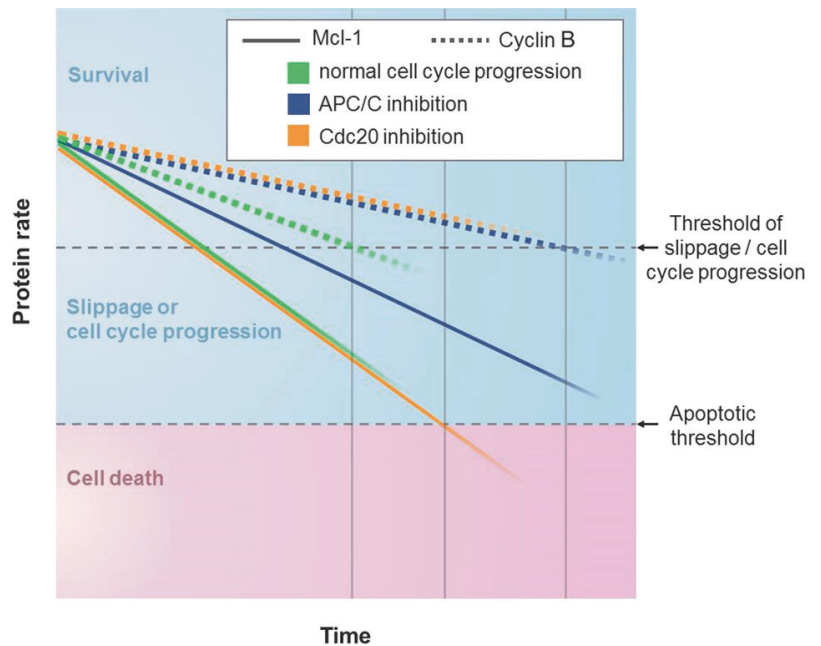

Fig. 2 Degradation of Mcl-1 upon treatment with antimitotic drugs. Mcl-1 is one of the key switches between prolonged arrest in mitosis and cell death. The level of Mcl-1 changes as the cell cycle progresses, peaking in $\mathrm{G} 2$ and declining in mitosis. Prolonged mitotic arrest eventually leads to a drop in Mcl-1 levels below the threshold of apoptosis induction. Degradation of Mcl-1 is responsible for the cell death induced by microtubule poisons [61]. However, which machinery controls proteasomal degradation of Mcl-1 during mitotic arrest is still debatable. Previously, APC/C ${ }^{\mathrm{Cdc} 20}$, Mule, and $\mathrm{SCF}^{\mathrm{FBW} 7}$ were reported to target Mcl-1 for proteasomal degradation in arrested cells $[59,61,83]$. It is noteworthy, though, that microtubule poisons lead to the degradation of cyclin $\mathrm{B}$, resulting in mitotic slippage. Hence, data concerning the roles of various ubiquitin ligases may reflect events in cells after mitotic slippage, but not in arrested ones. Recently, Allan et al. revised their previous data about the role of $\mathrm{APC} / \mathrm{C}^{\mathrm{Cdc20}}$ in the degradation of Mcl-1 during mitotic arrest (see the figure). Instead, APC/C (independently of its activator Cdc20) was shown to be a key determinant of this process [85]. According to the proposed model, low activity of APC/C provides a slow decrease in the level of Mcl-1 (blue line), which ultimately reaches the threshold of apoptosis induction. This coincides with a decrease in the level of cyclin B (dashed blue line) and, if the latter prevails, cells slip out of mitosis before apoptosis induction. Earlier, it was shown that targeting $\mathrm{Cdc} 20$ leads to an increase in the ratio of apoptotic/slipped cells in comparison with the action of microtubule poisons [86]. The model proposed by Allan et al. demonstrates the possible mechanism of this phenomenon. Microtubule poisons lead to the inhibition of $\mathrm{APC} / \mathrm{C}$, which affects the degradation of both Mcl-1 and cyclin B. However, while cyclin B requires $\mathrm{Cdc} 20$ for degradation, Mcl-1 does not. Consequently, targeting Cdc20 slows down the degradation of cyclin B (dashed orange line), but not the degradation of Mcl-1 (orange line), thus favoring apoptosis [85]. Meanwhile, during normal mitosis, the degradation of cyclin B (dashed green line) ensures cell cycle progression before the level of Mcl-1 (green line) drops below the threshold of apoptosis induction. Please note, the curves for Mcl-1 and cyclin B levels are not proportional to each other, so the level of Mcl-1 should not be directly compared with the level of cyclin B. In general, degradation of Mcl-1 during mitotic arrest depends on $\mathrm{APC} / \mathrm{C}$, while degradation of cyclin B depends on both APC/C and Cdc20. These data show the molecular basis of various outcomes after the treatment of cells with antimitotic drugs and the decisive role of Mcl-1 in determining cell fate.

C-terminal lysine residues of Mcl-1, but not those in the Nterminal regulatory region, were subjected to K63 ubiquitination by TRAF6 [87]. 
As the name implies, deubiquitinases reverse the process of ubiquitination, inhibiting proteasomal degradation of their substrates. Yet, USP9X, USP13, USP24, JOSD1, DUB3, and $\mathrm{Ku} 70$ were found to promote deubiquitination of Mcl-1. USP9X deubiquitinates Mcl-1, depending on the phosphorylation state of the degradation-associated residues Ser155, Ser159, and Thr163. The substitution of these residues with alanine favors interactions between USP9X and Mcl-1, whereas a phosphomimic $(\mathrm{S} 155 \mathrm{E}+\mathrm{S} 159 \mathrm{E}+$ T163E) mutant of Mcl-1 demonstrates a decreased affinity towards USP9X. Consistently, GSK-3 inhibition prevents stress-induced dissociation of USP9X from Mcl-1 [89]. Furthermore, Noxa was shown to disrupt USP9X/Mcl-1 interactions, resulting in ubiquitin-dependent degradation of Mcl-1 [72].

Similarly, deubiquitinase USP24 can interact with Mcl-1, while the knockdown of USP24 resulted in decreased Mcl-1 levels. No in vitro assays for direct deubiquitination of Mcl1 by USP24 were performed [90]. Next, it was reported that USP13 was a novel deubiquitinase for Mcl-1. Apparently, in several cancer cell lines, Mcl-1 stability depends on USP13 rather than USP9X [91]. Two recent studies revealed DUB3 and JOSD1 as deubiquitinases of Mcl-1 $[31,32]$. Overexpression of DUB3 resulted in an increase in the level of Mcl-1, while DUB3 knockdown led to increased ubiquitination of Mcl-1. Although no in vitro assay for direct deubiquitination of Mcl-1 was demonstrated, the interaction between DUB3 and the N-terminus of Mcl-1 suggests that DUB3 might act as a direct deubiquitinase of Mcl-1. It was also shown that among the three N-terminal lysines of Mcl-1 - K5, K40, and K136 - DUB3, as well as USP9X, promoted deubiquitination at K40 [31]. Similarly to DUB3, JOSD1 interacted with the N-terminus of Mcl-1, and it was demonstrated that JOSD1 directly cleaved the K48-linked polyubiquitin chains bound to Mcl-1 [32].

Somewhat unexpectedly, the DNA repair protein $\mathrm{Ku} 70$ appears to stabilize Mcl-1 through deubiquitination [92]. The deubiquitinating activity of $\mathrm{Ku} 70$ has been insufficiently explored, and, so far, Bax and Mcl-1 are the only known substrates for deubiquitination by $\mathrm{Ku} 70$ [92, 93]. It could be proposed that $\mathrm{Ku} 70$ regulates the interplay between the DNA damage response and apoptosis through the regulation of Mcl-1 or controls its nonapoptotic functions. Indeed, further studies are necessary to address these possibilities. Nevertheless, it is clear that ubiquitination and proteasomal degradation represent some of the most important mechanisms for the modulation of Mcl-1 levels.

\section{Mcl-1 downregulation during cell death execution}

Elimination of prosurvival factors is required for the efficient execution of cell death. During apoptosis, Mcl-1 is cleaved by executioner caspases at D127 and D157 [94] and Granzyme B at D117 and, to a lesser extent, at D127 and D157 [95]. Although the resulting C-terminal fragments of Mcl-1 are still able to form antiapoptotic BH3-binding groove, their binding profiles seem to be altered [94, 95]. There is some uncertainty about how Mcl-1 cleavage affects its functions. While several studies have demonstrated proapoptotic activity of Mcl-1 cleavage fragments [96, 97], others have failed to do so [94, 98]. The functions of Mcl-1 cleavage products seem to be context-dependent, and this issue requires further elucidation. Another mechanism of Mcl-1 downregulation during apoptosis is global mRNA decay by exonuclease DIS3 mitotic control homolog-like 2 (DIS3L2), which leads to the arrest of protein synthesis and a subsequent drop in Mcl-1 levels [99]. Taken together, these mechanisms ensure the elimination of Mcl-1 during execution of apoptotic cell death. This circumstance should be considered when interpreting the decrease in Mcl-1 levels, e.g., by western blot analysis, in response to different apoptosis-inducing agents since the downregulation of Mcl-1 could represent both a cause and/or a consequence of apoptosis.

\section{Dysregulation of $\mathrm{Mcl}-1$}

Overexpression of Mcl-1 confers high oncogenic potential due to the decreased susceptibility to apoptotic stimuli. The corresponding dysregulation may occur in two common ways. First, MCLl is the proposed amplification target gene, and cancer cells with amplifications in the MCL1 genomic locus depend on Mcl-1 for survival [100]. In addition, specific short sequence insertions in the MCLI promoter were shown to correlate with the increased expression of Mcl-1 and a worse prognosis in chronic lymphocytic leukemia patients [101]. Similar to the BCL2 proto-oncogene, MCL1 is located at a chromosomal fragile site [102]. However, unlike BCL2, MCL1 rarely undergoes chromosomal translocations [102]. Point mutations in MCL1 are also uncommon events, with no specific mutational hotspots identified [103]. Overall, genomic dysregulation of MCL1 mainly involves gene amplifications, but not translocations or point mutations.

Second, alterations in multiple signaling pathways and the regulatory mechanisms mentioned earlier may affect Mcl-1 expression. For example, in acute lymphoblastic leukemia cell lines, both stabilization (through phosphorylation of Thr92 and Thr163) and increased antiapoptotic activity (through phosphorylation of Ser64) of Mcl-1 contribute to acquired resistance to ABT-737 treatment [104]. Another regulator of $\mathrm{Mcl}-1$, the serine/threonine kinase GSK-3, plays dual roles in cancer [105]. Nevertheless, GSK-3 activation could be useful in overcoming the Mcl-1mediated resistance to apoptosis. Since Akt negatively 
regulates GSK-3 [57], targeting Akt leads to GSK-3dependent Mcl-1 degradation [80]. Next, reduced FBW7 activity results in the stabilization of Mcl-1 in cancer cell lines of different origins [106, 107]. Interestingly, FBW7mutant cancer cells exhibit resistance to ABT-737 and docetaxel, while being highly sensitive to HDAC inhibitors [108]. Hence, epigenetic regulation might represent a promising strategy for the treatment of tumors that overexpress Mcl-1. Of note, some types of histone modifications were shown to regulate Mcl-1 expression in cancer cells. In osteosarcoma cells, binding of histone $\mathrm{H} 3$ trimethylated at lys27 (H3K27me3), a mark of transcriptional repression, to the MCL1 gene locus was directly correlated with sensitivity to cisplatin [109]. Finally, monoubiquitination of $\mathrm{H} 2 \mathrm{~A}$ orchestrated by deubiquitinase BAP1 and ubiquitin ligase RNF2 was found to silence both Mcl-1 and Bcl-2 expression [110].

There are numerous other examples illustrating how cancer cells can abuse various molecular mechanisms in order to upregulate Mcl-1. Meanwhile, one of the most important issues is whether the mechanisms of Mcl-1 regulation listed above have clinical relevance. There are several studies that have demonstrated a correlation between Mcl-1 regulators and prognosis and/or Mcl-1 levels in patients. As such, in pancreatic cancer patients, a decrease in FBW7 expression correlates with Mcl-1 accumulation and a poor prognosis [111]. A correlation between USP9X and Mcl-1 expression was found in several cancers, including follicular lymphoma and colon adenocarcinoma. Moreover, in patients with multiple myeloma, an increase in USP9X mRNA was associated with a poor prognosis [89]. Immunohistochemistry analysis revealed a strong correlation between USP13 and Mcl-1 levels in ovarian cancer tissues [91]. Similar results were shown for the recently identified deubiquitinases of Mcl-1, JOSD1 and DUB3. In addition to the correlation between JOSD1 or DUB3 and Mcl-1 levels, all three proteins were correlated with a poor outcome in ovarian cancer patients [31,32].

Studying the relationship between Mcl-1 and its regulators might have practical significance for precision medicine approaches. For example, the expression of several ubiquitin ligases/deubiquitinases at mRNA levels could be assessed with convenient RNA-seq techniques to predict Mcl-1-dependence in tumors. However, since posttranslational regulation of Mcl-1 implies changes in Mcl-1 protein levels and not in mRNA abundance, more complicated approaches, such as immunohistochemistry, could be required to assess the increase/decrease in Mcl-1 levels. In this case, dysregulation of ubiquitin ligases/deubiquitinases of Mcl-1 could serve as a predictive biomarker for the use of Mcl-1-targeted therapies. In general, translating our knowledge of the regulation of Mcl-1 into clinical practice is highly relevant.

\section{Indirect inhibition of Mcl-1: to be or not to be?}

Previously, numerous attempts have been made to target various regulators of Mcl-1 in order to neutralize its antiapoptotic activity in cancer cells. Whereas preclinical studies have demonstrated promising results for a variety of agents and approaches, which could potentially downregulate $\mathrm{Mcl}-1$, only a few of them were translated into clinical trials. In particular, the CDK inhibitors alvocidib and dinaciclib were evaluated as potential indirect inhibitors of Mcl-1. However, the conducted trials failed to demonstrate the efficacy of the studied compounds in decreasing Mcl-1 levels. While several reports did not disclose the influence on Mcl-1 [112, 113], one report demonstrated only weak efficacy of alvocidib in the context of downregulation of Mcl-1 [114]. Nevertheless, new clinical trials with $\mathrm{CDK}$ inhibitors are being conducted focusing on changes in Mcl-1 levels as a pharmacodynamic effect (NCT04017546, NCT03739554) or Mcl-1-dependency as a biomarker of sensitivity (NCT03298984, NCT02520011). Hopefully, new studies will demonstrate better efficacy of CDK inhibitors as modulators of Mcl-1.

The rationale for the use of CDK inhibitors for targeting Mcl-1 is that these compounds block global mRNA synthesis, which results in a dramatic change in the level of short-lived proteins [115]. There are many other mechanisms through which potential indirect inhibitors of Mcl-1 could act. In theory, each node in the complex net of regulation of Mcl-1 could be targeted in order to downregulate this oncogenic protein. For example, WP1130, which inhibits several deubiquitinases, including USP9X and USP24, induced apoptosis in Mcl-1-dependent myeloma cells [90]. Inhibitors of mTORC1 might decrease Mcl-1 levels through suppression of CDT [48]. Mcl-1 can also be downregulated by calorie restriction [116], which represents a promising approach for cancer therapy [117]. Recent work demonstrates that feeding/fasting cycles in combination with metformin inhibit tumor growth through the downregulation of Mcl-1 in a GSK-3 $\beta$-dependent manner [118]. In addition, tyrosine kinase inhibitors (TKIs), as exemplified by sorafenib, lead to decreases in Mcl-1 through various mechanisms $[119,120]$. Pharmacological agents that upregulate $\mathrm{BH} 3$-only proteins targeting $\mathrm{Mcl}-1$ represent another tool for indirect inhibition of this protein [121, 122]. This is especially relevant for transcriptional inducers of Noxa, as this protein demonstrates high selectivity to Mcl-1 over other antiapoptotic proteins, Bcl-2 and Bcl-xL. In general, there are numerous ways of indirect inhibition of Mcl-1.

Meanwhile, recent advances in the development of small molecule inhibitors targeting Mcl-1 have provided us with powerful tools that could be used to block the antiapoptotic activity of Mcl-1. If these compounds could be effective in 
clinical settings, should we consider indirect inhibitors of Mcl-1 as potential drugs? There are at least two reasons why this question should be answered positively. First, indirect Mcl-1 targeting could be better for the inhibition of Mcl-1 specifically in cancer cells. Mcl-1 is essential for the survival of some types of normal cells, and BH3-mimetics would result in the inhibition of Mcl-1 both in normal cells and in cancer cells. If, for instance, Mcl-1 is upregulated due to the increased activity of some deubiquitinases, the inhibition of the "reason" (i.e., deubiquitinases, in this example) rather than the "consequence" (i.e., Mcl-1) would diminish Mcl-1 predominantly in cancer but not in normal cells. Secondly, compounds such as CDK inhibitors and TKIs influence multiple cellular pathways, and the decrease in the Mcl-1 level represents one of the possible mechanisms of their action. In case such therapeutic agents could efficiently downregulate $\mathrm{Mcl}-1$, its direct inhibition by BH3-mimetics could be dispensable. Altogether, we speculate that, at least in some cases, indirect inhibitors of Mcl-1 might be a more favorable option for cancer therapy instead of direct antagonists.

\section{Conclusion}

Here, we have shed light on the regulatory circuits that modulate the expression and activity of the antiapoptotic protein Mcl-1. As discussed above, Mcl-1 is a short-lived protein that can be regulated through distinct mechanisms, including posttranslational modifications. These features of Mcl-1 have been used in many experimental studies to target Mcl-1 in cancer cells. Yet, translating this knowledge for practical applications is of great importance. We anticipate that further studies will focus on correlative analyses between the expression of Mcl-1 and its regulators in patients, as well as on the significance of various patterns of expression for the prediction of therapy responses. With the development of next generation sequencing technologies, substantial progress should be done in the understanding of mechanisms relevant for the dysregulation of Mcl-1 in patients. This would give new options for precision medicine approaches and improve therapy for cancer patients.

Acknowledgements This work was supported by a grant from the Russian Science Foundation (17-75-20102). The work in the authors' laboratories is supported by grants from the Russian Foundation for Basic Research (19-015-00332, 18-29-09005), the Stockholm (181301) and Swedish (190345) Cancer Societies.

\section{Compliance with ethical standards}

Conflict of interest The authors declare that they have no conflict of interest.
Publisher's note Springer Nature remains neutral with regard to jurisdictional claims in published maps and institutional affiliations.

\section{References}

1. Kozopas KM, Yang T, Buchan HL, Zhou P, Craig RW. MCL1, a gene expressed in programmed myeloid cell differentiation, has sequence similarity to BCL2. Proc Natl Acad Sci USA. 1993;90:3516-20.

2. Lin EY, Orlofsky A, Berger MS, Prystowsky MB. Characterization of A1, a novel hemopoietic-specific early-response gene with sequence similarity to bcl-2. J Immunol. 1993;151: 1979-88.

3. Boise LH, González-García M, Postema CE, Ding L, Lindsten T, Turka LA, et al. bcl-x, a bcl-2-related gene that functions as a dominant regulator of apoptotic cell death. Cell. 1993;74:597-608.

4. Oltvai ZN, Milliman CL, Korsmeyer SJ. Bcl-2 heterodimerizes in vivo with a conserved homolog, Bax, that accelerates programmed cell death. Cell. 1993;74:609-19.

5. Vaux DL, Cory S, Adams JM. Bcl-2 gene promotes haemopoietic cell survival and cooperates with c-myc to immortalize pre-B cells. Nature. 1988;335:440-2.

6. Merino D, Kelly GL, Lessene G, Wei AH, Roberts AW, Strasser A. BH3-mimetic drugs: blazing the trail for new cancer medicines. Cancer Cell. 2018;34:879-91.

7. Singh R, Letai A, Sarosiek K. Regulation of apoptosis in health and disease: the balancing act of BCL-2 family proteins. Nat Rev Mol Cell Biol. 2019;20:175-93.

8. Hird AW, Tron AE. Recent advances in the development of Mcl1 inhibitors for cancer therapy. Pharm Ther. 2019;198:59-67.

9. Senichkin VV, Streletskaia AY, Zhivotovsky B, Kopeina GS. Molecular comprehension of Mcl-1: from gene structure to cancer therapy. Trends Cell Biol. 2019. https://doi.org/10.1016/j. tcb.2019.03.004.

10. Craig RW. MCL1 provides a window on the role of the BCL2 family in cell proliferation, differentiation and tumorigenesis. Leukemia. 2002;16:444-54.

11. Thomas LW, Lam C, Edwards SW. Mcl-1; the molecular regulation of protein function. FEBS Lett. 2010;584:2981-9.

12. Gores GJ, Kaufmann SH. Selectively targeting Mcl-1 for the treatment of acute myelogenous leukemia and solid tumors. Genes Dev. 2012;26:305-11.

13. Mojsa B, Lassot I, Desagher S. Mcl-1 ubiquitination: unique regulation of an essential survival protein. Cells. 2014;3:418-37.

14. Opferman JT. Attacking cancer's Achilles heel: antagonism of anti-apoptotic BCL-2 family members. FEBS J. 2016;283: 2661-75.

15. Czabotar PE, Lessene G, Strasser A, Adams JM. Control of apoptosis by the BCL-2 protein family: implications for physiology and therapy. Nat Rev Mol Cell Biol. 2013;15:49-63.

16. Zou H, Henzel WJ, Liu X, Lutschg A, Wang X. Apaf-1, a human protein homologous to $\mathrm{C}$. elegans CED-4, participates in cytochrome c-dependent activation of caspase-3. Cell. 1997;90: 405-13.

17. Konopleva M, Contractor R, Tsao T, Samudio I, Ruvolo PP, Kitada S, et al. Mechanisms of apoptosis sensitivity and resistance to the $\mathrm{BH} 3$ mimetic ABT-737 in acute myeloid leukemia. Cancer Cell. 2006;10:375-88.

18. Rogers S, Wells R, Rechsteiner M. Amino acid sequences common to rapidly degraded proteins: the PEST hypothesis. Science. 1986;234:364-8.

19. Liu H, Peng H-W, Cheng Y-S, Yuan HS, Yang-Yen H-F. Stabilization and enhancement of the antiapoptotic activity of mcl-1 by TCTP. Mol Cell Biol. 2005;25:3117-26. 
20. Bingle CD, Craig RW, Swales BM, Singleton V, Zhou P, Whyte MKB. Exon skipping in Mcl-1 results in a Bcl-2 homology domain 3 only gene product that promotes cell death. J Biol Chem. 2000;275:22136-46.

21. Kim J-H, Sim S-H, Ha H-J, Ko J-J, Lee K, Bae J. MCL-1ES, a novel variant of MCL-1, associates with MCL-1L and induces mitochondrial cell death. FEBS Lett. 2009;583:2758-64.

22. Opferman JT, Letai A, Beard C, Sorcinelli MD, Ong CC, Korsmeyer SJ. Development and maintenance of B and T lymphocytes requires antiapoptotic MCL-1. Nature. 2003;426: 671-6.

23. Arbour N, Vanderluit JL, Le Grand JN, Jahani-Asl A, Ruzhynsky VA, Cheung ECC, et al. Mcl-1 is a key regulator of apoptosis during CNS development and after DNA damage. J Neurosci. 2008;28:6068-78.

24. Wang X, Bathina M, Lynch J, Koss B, Calabrese C, Frase S, et al. Deletion of MCL-1 causes lethal cardiac failure and mitochondrial dysfunction. Genes Dev. 2013;27:1351-64.

25. Xiang Z, Luo H, Payton JE, Cain J, Ley TJ, Opferman JT, et al. Mcl1 haploinsufficiency protects mice from Myc-induced acute myeloid leukemia. J Clin Invest. 2010;120:2109-18.

26. Sieghart W, Losert D, Strommer S, Cejka D, Schmid K, RasoulRockenschaub S, et al. Mcl-1 overexpression in hepatocellular carcinoma: a potential target for antisense therapy. J Hepatol. 2006;44:151-7.

27. Wesarg E, Hoffarth S, Wiewrodt R, Kröll M, Biesterfeld S, Huber C, et al. Targeting BCL-2 family proteins to overcome drug resistance in non-small cell lung cancer. Int $\mathrm{J}$ Cancer. 2007;121:2387-94.

28. Campbell KJ, Dhayade S, Ferrari N, Sims AH, Johnson E, Mason SM, et al. MCL-1 is a prognostic indicator and drug target in breast cancer. Cell Death Dis. 2018;9:19.

29. Uhlen M, Zhang C, Lee S, Sjöstedt E, Fagerberg L, Bidkhori G, et al. A pathology atlas of the human cancer transcriptome. Science. 2017;357:eaan2507.

30. Niu X, Zhao J, Ma J, Xie C, Edwards H, Wang G, et al. Binding of released Bim to Mcl-1 is a mechanism of intrinsic resistance to ABT-199 which can be overcome by combination with daunorubicin or cytarabine in AML cells. Clin Cancer Res. 2016;22:4440-51.

31. Wu X, Luo Q, Zhao P, Chang W, Wang Y, Shu T, et al. MGMTactivated DUB3 stabilizes MCL1 and drives chemoresistance in ovarian cancer. Proc Natl Acad Sci USA. 2019;116:2961-6.

32. Wu X, Luo Q, Zhao P, Chang W, Wang Y, Shu T, et al. JOSD1 inhibits mitochondrial apoptotic signalling to drive acquired chemoresistance in gynaecological cancer by stabilizing MCL1. Cell Death Differ. 2019. https://doi.org/10.1038/s41418-0190339-0.

33. Konopleva M, Pollyea DA, Potluri J, Chyla B, Hogdal L, Busman $\mathrm{T}$, et al. Efficacy and biological correlates of response in a phase II study of venetoclax monotherapy in patients with acute myelogenous leukemia. Cancer Discov. 2016;6:1106-17.

34. Kaufmann SH, Karp JE, Svingen PA, Krajewski S, Burke PJ, Gore SD, et al. Elevated expression of the apoptotic regulator Mcl-1 at the time of leukemic relapse. Blood. 1998;91:991-1000.

35. Jourdan M, De Vos J, Mechti N, Klein B. Regulation of Bcl-2family proteins in myeloma cells by three myeloma survival factors: interleukin-6, interferon-alpha and insulin-like growth factor 1. Cell Death Differ. 2000;7:1244-52.

36. Schulze-Bergkamen H, Brenner D, Krueger A, Suess D, Fas SC, Frey CR, et al. Hepatocyte growth factor induces Mcl-1 in primary human hepatocytes and inhibits CD95-mediated apoptosis via Akt. Hepatology. 2004;39:645-54.

37. Leu C-M, Chang C, Hu C. Epidermal growth factor (EGF) suppresses staurosporine-induced apoptosis by inducing mcl-1 via the mitogen-activated protein kinase pathway. Oncogene. 2000;19:1665-75.

38. Booy EP, Henson ES, Gibson SB. Epidermal growth factor regulates Mcl-1 expression through the MAPK-Elk-1 signalling pathway contributing to cell survival in breast cancer. Oncogene. 2011;30:2367-78.

39. Yang T, Buchan HL, Townsend KJ, Craig RW. MCL-1, a member of the BCL-2 family, is induced rapidly in response to signals for cell differentiation or death, but not to signals for cell proliferation. J Cell Physiol. 1996;166:523-36.

40. Jiang CC, Lucas K, Avery-Kiejda KA, Wade M, deBock CE, Thorne RF, et al. Up-regulation of Mcl-1 Is critical for survival of human melanoma cells upon endoplasmic reticulum stress. Cancer Res. 2008;68:6708-17.

41. Piret J-P, Minet E, Cosse J-P, Ninane N, Debacq C, Raes M, et al. Hypoxia-inducible factor-1-dependent overexpression of myeloid cell factor-1 protects hypoxic cells against tert-butyl hydroperoxide-induced apoptosis. J Biol Chem. 2005;280: 9336-44.

42. Sheng Z, Li L, Zhu LJ, Smith TW, Demers A, Ross AH, et al. A genome-wide RNA interference screen reveals an essential CREB3L2-ATF5-MCL1 survival pathway in malignant glioma with therapeutic implications. Nat Med. 2010;16:671-7.

43. Kiprianova I, Remy J, Milosch N, Mohrenz IV, Seifert V, Aigner A, et al. Sorafenib sensitizes glioma cells to the BH3 mimetic ABT-737 by targeting MCL1 in a STAT3-dependent manner. Neoplasia. 2015;17:564-73.

44. Cui J, Placzek WJ. Post-transcriptional regulation of antiapoptotic BCL2 family members. Int J Mol Sci. 2018; 19. https://doi.org/10.3390/IJMS19010308.

45. Wang KC, Chang HY. Molecular mechanisms of long noncoding RNAs. Mol Cell. 2011;43:904-14.

46. Fritsch RM, Schneider G, Saur D, Scheibel M, Schmid RM. Translational repression of MCL-1 couples stress-induced eIF2 $\alpha$ phosphorylation to mitochondrial apoptosis initiation. J Biol Chem. 2007;282:22551-62.

47. De Benedetti A, Graff JR. eIF-4E expression and its role in malignancies and metastases. Oncogene. 2004;23:3189-99.

48. Mills JR, Hippo Y, Robert F, Chen SMH, Malina A, Lin C-J, et al. mTORC1 promotes survival through translational control of Mcl-1. Proc Natl Acad Sci. 2008;105:10853-8.

49. Pradelli LA, Bénéteau M, Chauvin C, Jacquin MA, Marchetti S, Muñoz-Pinedo $\mathrm{C}$, et al. Glycolysis inhibition sensitizes tumor cells to death receptors-induced apoptosis by AMP kinase activation leading to $\mathrm{Mcl}-1$ block in translation. Oncogene. 2010;29:1641-52.

50. Tailler M, Lindqvist LM, Gibson L, Adams JM. By reducing global mRNA translation in several ways, 2-deoxyglucose lowers MCL-1 protein and sensitizes hemopoietic tumor cells to BH3 mimetic ABT737. Cell Death Differ. 2018. https://doi.org/ 10.1038/s41418-018-0244-y.

51. Kim SM, Yun MR, Hong YK, Solca F, Kim JH, Kim HJ, et al. Glycolysis inhibition sensitizes non-small cell lung cancer with T790M mutation to irreversible EGFR inhibitors via translational suppression of Mcl-1 by AMPK activation. Mol Cancer Ther. 2013;12:2145-56.

52. Pawson T, Scott JD. Protein phosphorylation in signaling-50 years and counting. Trends Biochem Sci. 2005;30:286-90.

53. Zamaraev AV, Kopeina GS, Prokhorova EA, Zhivotovsky B, Lavrik IN. Post-translational modification of caspases: the other side of apoptosis regulation. Trends Cell Biol. 2017;27:322-39.

54. Domina AM, Vrana JA, Gregory MA, Hann SR, Craig RW. MCL1 is phosphorylated in the PEST region and stabilized upon ERK activation in viable cells and at additional sites with cytotoxic okadaic acid or taxol. Oncogene. 2004;23:5301-15. 
55. Ding Q, Huo L, Yang J-Y, Xia W, Wei Y, Liao Y, et al. Downregulation of myeloid cell leukemia-1 through inhibiting Erk/Pin 1 pathway by sorafenib facilitates chemosensitization in breast cancer. Cancer Res. 2008;68:6109-17.

56. Inuzuka H, Shaik S, Onoyama I, Gao D, Tseng A, Maser RS, et al. $\mathrm{SCF}(\mathrm{FBW} 7)$ regulates cellular apoptosis by targeting MCL1 for ubiquitylation and destruction. Nature. 2011;471: 104-9.

57. Maurer U, Charvet C, Wagman AS, Dejardin E, Green DR. Glycogen synthase kinase-3 regulates mitochondrial outer membrane permeabilization and apoptosis by destabilization of MCL-1. Mol Cell. 2006;21:749-60.

58. Ding Q, He X, Hsu J-M, Xia W, Chen C-T, Li L-Y, et al. Degradation of Mcl-1 by beta-TrCP mediates glycogen synthase kinase 3-induced tumor suppression and chemosensitization. Mol Cell Biol. 2007;27:4006-17.

59. Wertz IE, Kusam S, Lam C, Okamoto T, Sandoval W, Anderson DJ, et al. Sensitivity to antitubulin chemotherapeutics is regulated by MCL1 and FBW7. Nature. 2011;471:110-4.

60. Tong J, Zheng X, Tan X, Fletcher R, Nikolovska-Coleska Z, Yu $\mathrm{J}$, et al. Mcl-1 phosphorylation without degradation mediates sensitivity to HDAC inhibitors by liberating BH3-only proteins. Cancer Res. 2018;78:4704-15.

61. Harley ME, Allan LA, Sanderson HS, Clarke PR. Phosphorylation of Mcl-1 by CDK1-cyclin B1 initiates its Cdc20dependent destruction during mitotic arrest. EMBO J. 2010;29: 2407-20.

62. Chu R, Alford SE, Hart K, Kothari A, Mackintosh SG, Kovak $\mathrm{MR}$, et al. Mitotic arrest-induced phosphorylation of Mcl-1 revisited using two-dimensional gel electrophoresis and phosphoproteomics: nine phosphorylation sites identified. Oncotarget. 2016;7:78958-70.

63. Kobayashi S, Lee S-H, Meng XW, Mott JL, Bronk SF, Werneburg NW, et al. Serine 64 phosphorylation enhances the antiapoptotic function of Mcl-1. J Biol Chem. 2007;282: 18407-17.

64. Nakajima W, Sharma K, Lee JY, Maxim NT, Hicks MA, Vu T$\mathrm{T}$, et al. DNA damaging agent-induced apoptosis is regulated by MCL-1 phosphorylation and degradation mediated by the Noxa/ MCL-1/CDK2 complex. Oncotarget. 2016;7:36353-65.

65. Inoshita S, Takeda K, Hatai T, Terada Y, Sano M, Hata J, et al. Phosphorylation and inactivation of myeloid cell leukemia 1 by JNK in response to oxidative stress. J Biol Chem. 2002;277: 43730-4.

66. Willis SN, Chen L, Dewson G, Wei A, Naik E, Fletcher JI, et al. Proapoptotic Bak is sequestered by Mcl-1 and Bcl-xL, but not Bcl-2, until displaced by BH3-only proteins. Genes Dev. 2005;19:1294-305.

67. Chau V, Tobias JW, Bachmair A, Marriott D, Ecker DJ, Gonda $\mathrm{DK}$, et al. A multiubiquitin chain is confined to specific lysine in a targeted short-lived protein. Science. 1989;243:1576-83.

68. Stewart DP, Koss B, Bathina M, Perciavalle RM, Bisanz K, Opferman JT. Ubiquitin-independent degradation of antiapoptotic MCL-1. Mol Cell Biol. 2010;30:3099-110.

69. Ben-Nissan G, Sharon M. Regulating the $20 \mathrm{~S}$ proteasome ubiquitin-independent degradation pathway. Biomolecules. 2014; 4:862-84.

70. Zhong Q, Gao W, Du F, Wang X. Mule/ARF-BP1, a BH3-only E3 ubiquitin ligase, catalyzes the polyubiquitination of Mcl-1 and regulates apoptosis. Cell. 2005;121:1085-95.

71. Warr MR, Acoca S, Liu Z, Germain M, Watson M, Blanchette $\mathrm{M}$, et al. BH3-ligand regulates access of MCL-1 to its E3 ligase. FEBS Lett. 2005;579:5603-8.

72. Gomez-Bougie P, Ménoret E, Juin P, Dousset C, PellatDeceunynck C, Amiot M. Noxa controls Mule-dependent Mcl-
1 ubiquitination through the regulation of the Mcl-1/USP9X interaction. Biochem Biophys Res Commun. 2011;413:460-4.

73. Hao Z, Duncan GS, Su Y-W, Li WY, Silvester J, Hong C, et al. The E3 ubiquitin ligase Mule acts through the ATM-p53 axis to maintain B lymphocyte homeostasis. J Exp Med. 2012;209: 173-86.

74. Myant KB, Cammareri P, Hodder MC, Wills J, Von Kriegsheim A, Győrffy B, et al. HUWE1 is a critical colonic tumour suppressor gene that prevents MYC signalling, DNA damage accumulation and tumour initiation. EMBO Mol Med. 2017;9: 181-97.

75. Subramanian A, Andronache A, Li Y-C, Wade M. Inhibition of MARCH5 ubiquitin ligase abrogates MCL1-dependent resistance to BH3 mimetics via NOXA. Oncotarget. 2016;7:15986-6002.

76. Cherok E, Xu S, Li S, Das S, Meltzer WA, Zalzman M, et al. Novel regulatory roles of Mff and Drp1 in E3 ubiquitin ligase MARCH5-dependent degradation of MiD49 and Mcl1 and control of mitochondrial dynamics. Mol Biol Cell. 2017;28: 396-410.

77. Zhang C, Lee S, Peng Y, Bunker E, Giaime E, Shen J, et al. PINK1 triggers autocatalytic activation of Parkin to specify cell fate decisions. Curr Biol. 2014;24:1854-65.

78. Carroll RG, Hollville E, Martin SJ. Parkin sensitizes toward apoptosis induced by mitochondrial depolarization through promoting degradation of Mcl-1. Cell Rep. 2014;9:1538-53.

79. Feng C, Yang F, Wang J. FBXO4 inhibits lung cancer cell survival by targeting Mcl-1 for degradation. Cancer Gene Ther. 2017;24:342-7.

80. Ren H, Koo J, Guan B, Yue P, Deng X, Chen M, et al. The E3 ubiquitin ligases $\beta$-TrCP and FBXW7 cooperatively mediates GSK3-dependent Mcl-1 degradation induced by the Akt inhibitor API-1, resulting in apoptosis. Mol Cancer. 2013;12:146.

81. Mori A, Masuda K, Ohtsuka H, Shijo M, Ariake K, Fukase K, et al. FBXW7 modulates malignant potential and cisplatininduced apoptosis in cholangiocarcinoma through NOTCH1 and MCL1. Cancer Sci. 2018;109:3883-95.

82. Magiera MM, Mora S, Mojsa B, Robbins I, Lassot I, Desagher S. Trim17-mediated ubiquitination and degradation of Mcl-1 initiate apoptosis in neurons. Cell Death Differ. 2013;20:281-92.

83. Shi J, Zhou Y, Huang H-C, Mitchison TJ. Navitoclax (ABT-263) accelerates apoptosis during drug-induced mitotic arrest by antagonizing Bcl-xL. Cancer Res. 2011;71:4518-26.

84. Sloss O, Topham C, Diez M, Taylor S. Mcl-1 dynamics influence mitotic slippage and death in mitosis. Oncotarget. 2016;7:5176-92.

85. Allan LA, Skowyra A, Rogers KI, Zeller D, Clarke PR. Atypical APC/C-dependent degradation of Mcl-1 provides an apoptotic timer during mitotic arrest. EMBO J. 2018; 37. https://doi.org/ 10.15252/embj.201796831.

86. Huang H-C, Shi J, Orth JD, Mitchison TJ. Evidence that mitotic exit is a better cancer therapeutic target than spindle assembly. Cancer Cell. 2009;16:347-58.

87. Choi YB, Harhaj EW. HTLV-1 tax stabilizes MCL-1 via TRAF6dependent K63-linked polyubiquitination to promote cell survival and transformation. PLoS Pathog. 2014;10:e1004458.

88. Li Z, Younger K, Gartenhaus R, Joseph AM, Hu F, Baer MR, et al. Inhibition of IRAK1/4 sensitizes T cell acute lymphoblastic leukemia to chemotherapies. J Clin Invest. 2015;125:1081-97.

89. Schwickart M, Huang X, Lill JR, Liu J, Ferrando R, French DM, et al. Deubiquitinase USP9X stabilizes MCL1 and promotes tumour cell survival. Nature. 2010;463:103-7.

90. Peterson LF, Sun H, Liu Y, Potu H, Kandarpa M, Ermann M, et al. Targeting deubiquitinase activity with a novel smallmolecule inhibitor as therapy for B-cell malignancies. Blood. 2015;125:3588-97. 
91. Zhang S, Zhang M, Jing Y, Yin X, Ma P, Zhang Z, et al. Deubiquitinase USP13 dictates MCL1 stability and sensitivity to BH3 mimetic inhibitors. Nat Commun. 2018;9:215.

92. Wang B, Xie M, Li R, Owonikoko TK, Ramalingam SS, Khuri FR, et al. Role of Ku70 in deubiquitination of Mcl-1 and suppression of apoptosis. Cell Death Differ. 2014;21: 1160-9.

93. Amsel AD, Rathaus M, Kronman N, Cohen HY. Regulation of the proapoptotic factor Bax by Ku70-dependent deubiquitylation. Proc Natl Acad Sci USA. 2008;105:5117-22.

94. Clohessy JG, Zhuang J, Brady HJM. Characterisation of Mcl-1 cleavage during apoptosis of haematopoietic cells. $\mathrm{Br} \mathrm{J}$ Haematol. 2004;125:655-65.

95. Han J, Goldstein LA, Gastman BR, Rabinovitz A, Rabinowich H. Disruption of Mcl-1-Bim complex in granzyme B-mediated mitochondrial apoptosis. J Biol Chem. 2005;280:16383-92.

96. Weng C, Li Y, Xu D, Shi Y, Tang H. Specific cleavage of Mcl-1 by caspase-3 in tumor necrosis factor-related apoptosis-inducing Ligand (TRAIL)-induced apoptosis in Jurkat leukemia T Cells. J Biol Chem. 2005;280:10491-10500.

97. Fan F, Tonon G, Bashari MH, Vallet S, Antonini E, Goldschmidt $\mathrm{H}$, et al. Targeting Mcl-1 for multiple myeloma (MM) therapy: drug-induced generation of Mcl-1 fragment Mcl-1128-350 triggers MM cell death via c-Jun upregulation. Cancer Lett. 2014;343:286-94.

98. Herrant M, Jacquel A, Marchetti S, Belhacène N, Colosetti P, Luciano F, et al. Cleavage of Mcl-1 by caspases impaired its ability to counteract Bim-induced apoptosis. Oncogene. 2004;23: 7863-73.

99. Thomas MP, Liu X, Whangbo J, McCrossan G, Sanborn KB, Basar E, et al. Apoptosis triggers specific, rapid, and global mRNA decay with $3^{\prime}$ uridylated intermediates degraded by DIS3L2. Cell Rep. 2015;11:1079-89.

100. Beroukhim R, Mermel CH, Porter D, Wei G, Raychaudhuri S, Donovan $\mathrm{J}$, et al. The landscape of somatic copy-number alteration across human cancers. Nature. 2010;463:899-905.

101. Moshynska O, Sankaran K, Pahwa P, Saxena A. Prognostic significance of a short sequence insertion in the MCL-1 promoter in chronic lymphocytic leukemia. J Natl Cancer Inst. 2004;96: 673-82.

102. Fernández-Marrero Y, Spinner S, Kaufmann T, Jost PJ. Survival control of malignant lymphocytes by anti-apoptotic MCL-1. Leukemia. 2016;30:2152-9.

103. Forbes SA, Beare D, Boutselakis H, Bamford S, Bindal N, Tate J, et al. COSMIC: somatic cancer genetics at high-resolution. Nucleic Acids Res. 2017;45:D777-D783.

104. Mazumder S, Choudhary GS, Al-Harbi S, Almasan A. Mcl-1 Phosphorylation defines ABT-737 resistance that can be overcome by increased NOXA expression in leukemic B cells. Cancer Res. 2012;72:3069-79.

105. Mancinelli R, Carpino G, Petrungaro S, Mammola CL, Tomaipitinca L, Filippini A, et al. Multifaceted roles of GSK-3 in cancer and autophagy-related diseases. Oxid Med Cell Longev. 2017;2017:4629495.

106. Koo J, Yue P, Deng X, Khuri FR, Sun S-Y. mTOR complex 2 stabilizes Mcl-1 protein by suppressing its glycogen synthase kinase 3-dependent and SCF-FBXW7-mediated degradation. Mol Cell Biol. 2015;35:2344-55.

107. Tong J, Tan S, Zou F, Yu J, Zhang L. FBW7 mutations mediate resistance of colorectal cancer to targeted therapies by blocking Mcl-1 degradation. Oncogene. 2017;36:787-96.

108. He L, Torres-Lockhart K, Forster N, Ramakrishnan S, Greninger $\mathrm{P}$, Garnett MJ, et al. Mcl-1 and FBW7 control a dominant survival pathway underlying HDAC and Bcl-2 inhibitor synergy in squamous cell carcinoma. Cancer Discov. 2013;3:324-37.
109. He C, Sun J, Liu C, Jiang Y, Hao Y. Elevated H3K27me3 levels sensitize osteosarcoma to cisplatin. Clin Epigenetics. 2019; 11. https://doi.org/10.1186/s13148-018-0605-x.

110. He M, Chaurushiya MS, Webster JD, Kummerfeld S, Reja R, Chaudhuri $\mathrm{S}$, et al. Intrinsic apoptosis shapes the tumor spectrum linked to inactivation of the deubiquitinase BAP1. Science. 2019;364:283-5.

111. Ishii N, Araki K, Yokobori T, Gantumur D, Yamanaka T, Altan $\mathrm{B}$, et al. Reduced FBXW7 expression in pancreatic cancer correlates with poor prognosis and chemotherapeutic resistance via accumulation of MCL1. Oncotarget. 2017;8:112636-46.

112. Maddocks K, Wei L, Rozewski D, Jiang Y, Zhao Y, Adusumilli $\mathrm{M}$, et al. Reduced occurrence of tumor flare with flavopiridol followed by combined flavopiridol and lenalidomide in patients with relapsed chronic lymphocytic leukemia (CLL). Am J Hematol. 2015;90:327-33.

113. Mitri Z, Karakas C, Wei C, Briones B, Simmons H, Ibrahim N, et al. A phase 1 study with dose expansion of the CDK inhibitor dinaciclib (SCH 727965) in combination with epirubicin in patients with metastatic triple negative breast cancer. Invest $\mathrm{N}$. Drugs. 2015;33:890-4.

114. Karp JE, Smith BD, Resar LS, Greer JM, Blackford A, Zhao M, et al. Phase 1 and pharmacokinetic study of bolus-infusion flavopiridol followed by cytosine arabinoside and mitoxantrone for acute leukemias. Blood. 2011;117:3302-10.

115. Kadia TM, Kantarjian HM, Konopleva M. Myeloid cell leukemia-1 dependence in acute myeloid leukemia: a novel approach to patient therapy. Oncotarget 2019;10:1250-65.

116. Senichkin VV, Kopeina GS, Prokhorova EA, Zamaraev AV, Lavrik IN, Zhivotovsky B. Modulation of Mcl-1 transcription by serum deprivation sensitizes cancer cells to cisplatin. Biochim Biophys Acta Gen Subj. 2018;1862:557-66.

117. Kopeina GS, Senichkin VV, Zhivotovsky B. Caloric restriction -a promising anti-cancer approach: from molecular mechanisms to clinical trials. Biochim Biophys Acta Rev Cancer 2017;1867:29-41.

118. Elgendy M, Cirò M, Hosseini A, Weiszmann J, Mazzarella L, Ferrari E, et al. Combination of hypoglycemia and metformin impairs tumor metabolic plasticity and growth by modulating the PP2A-GSK3 $\beta-M C L-1$ axis. Cancer Cell. 2019;35:798-815.e5.

119. Rahmani M, Davis EM, Bauer C, Dent P, Grant S. Apoptosis induced by the kinase inhibitor BAY 43-9006 in human leukemia cells involves down-regulation of Mcl-1 through inhibition of translation. J Biol Chem. 2005;280:35217-27.

120. Wang R, Xia L, Gabrilove J, Waxman S, Jing Y. Sorafenib inhibition of Mcl-1 accelerates ATRA-induced apoptosis in differentiation-responsive AML cells. Clin Cancer Res. 2016;22: 1211-21.

121. Gomez-Bougie P, Wuillème-Toumi S, Ménoret E, Trichet V, Robillard N, Philippe M, et al. Noxa up-regulation and Mcl-1 cleavage are associated to apoptosis induction by bortezomib in multiple myeloma. Cancer Res. 2007;67:5418-24.

122. Lamothe B, Wierda WG, Keating MJ, Gandhi V. Carfilzomib triggers cell death in chronic lymphocytic leukemia by inducing proapoptotic and endoplasmic reticulum stress responses. Clin Cancer Res. 2016;22:4712-26.

123. Bhattacharyya A, Chattopadhyay R, Hall EH, Mebrahtu ST, Ernst PB, Crowe SE. Mechanism of hypoxia-inducible factor $1 \alpha$ mediated Mcl1 regulation in Helicobacter pylori-infected human gastric epithelium. Am J Physiol Gastrointest Liver Physiol. 2010;299. https://doi.org/10.1152/ajpgi.00372.2010.

124. Townsend KJ, Zhou P, Qian L, Bieszczad CK, Lowrey CH, Yen A, et al. Regulation of MCL1 through a serum response factor/ Elk-1-mediated mechanism links expression of a viabilitypromoting member of the BCL2 family to the induction of 
hematopoietic cell differentiation. J Biol Chem. 1999;274: 1801-13.

125. Day BW, Stringer BW, Spanevello MD, Charmsaz S, Jamieson PR, Ensbey KS, et al. ELK4 neutralization sensitizes glioblastoma to apoptosis through downregulation of the antiapoptotic protein Mcl-1. Neuro Oncol. 2011;13:1202-12.

126. Hu J, Dang N, Menu E, De Bruyne E, De Bryune E, Xu D, et al. Activation of ATF4 mediates unwanted Mcl-1 accumulation by proteasome inhibition. Blood. 2012;119:826-37.

127. Chen Y-J, Huang C-H, Shi Y-J, Lee Y-C, Wang L-J, Chang L-S. The suppressive effect of arsenic trioxide on TET2-FOXP3-LynAkt axis-modulated MCL1 expression induces apoptosis in human leukemia cells. Toxicol Appl Pharm. 2018;358:43-55.

128. Isomoto H, Kobayashi S, Werneburg NW, Bronk SF, Guicciardi ME, Frank DA, et al. Interleukin 6 upregulates myeloid cell leukemia-1 expression through a STAT3 pathway in cholangiocarcinoma cells. Hepatology. 2005;42:1329-38.

129. Becker TM, Boyd SC, Mijatov B, Gowrishankar K, Snoyman S, Pupo GM, et al. Mutant B-RAF-Mcl-1 survival signaling depends on the STAT3 transcription factor. Oncogene. 2014;33: 1158-66.

130. Dong L, Jiang CC, Thorne RF, Croft A, Yang F, Liu H, et al. Ets-1 mediates upregulation of Mcl-1 downstream of XBP-1 in human melanoma cells upon ER stress. Oncogene. 2011;30: 3716.

131. Ricci MS, Kim S-H, Ogi K, Plastaras JP, Ling J, Wang W, et al. Reduction of TRAIL-induced Mcl-1 and cIAP2 by c-Myc or sorafenib sensitizes resistant human cancer cells to TRAILinduced death. Cancer Cell. 2007;12:66-80.

132. Labisso WL, Wirth M, Stojanovic N, Stauber RH, Schnieke A, Schmid RM, et al. MYC directs transcription of MCL1 and eIF4E genes to control sensitivity of gastric cancer cells toward HDAC inhibitors. Cell Cycle. 2012;11:1593-602.

133. Schacter JL, Henson ES, Gibson SB. Estrogen regulation of antiapoptotic Bcl-2 family member Mcl-1 expression in breast cancer cells. PLoS ONE. 2014;9:e100364.

134. Rosato RR, Almenara JA, Kolla SS, Maggio SC, Coe S, Giménez MS, et al. Mechanism and functional role of XIAP and Mcl-1 down-regulation in flavopiridol/vorinostat antileukemic interactions. Mol Cancer Ther. 2007;6:692-702.

135. Akgul C, Turner PC, White MRH, Edwards* SW. Functional analysis of the human MCL-1 gene. Cell Mol Life Sci. 2000;57: 684-91.

136. Wang S-H, Zhang W-J, Wu X-C, Weng M-Z, Zhang M-D, Cai $\mathrm{Q}$, et al. The IncRNA MALAT1 functions as a competing endogenous RNA to regulate MCL-1 expression by sponging miR-363-3p in gallbladder cancer. J Cell Mol Med. 2016;20: 2299-308.

137. Wang H, Wang L, Zhang G, Lu C, Chu H, Yang R, et al. MALAT1/miR-101-3p/MCL1 axis mediates cisplatin resistance in lung cancer. Oncotarget. 2018;9:7501-12.
138. Stamato MA, Juli G, Romeo E, Ronchetti D, Arbitrio M, Caracciolo $\mathrm{D}$, et al. Inhibition of EZH2 triggers the tumor suppressive miR-29b network in multiple myeloma. Oncotarget. 2017;8:106527-37.

139. Liu B, Cao W, Xue J. LncRNA ANRIL protects against oxygen and glucose deprivation (OGD)-induced injury in PC-12 cells: potential role in ischaemic stroke. Artif Cells Nanomed Biotechnol. 2019;47:1384-95.

140. Chen D, Lu X, Yang F, Xing N. Circular RNA circHIPK3 promotes cell proliferation and invasion of prostate cancer by sponging miR-193a-3p and regulating MCL1 expression. Cancer Manag Res. 2019;11:1415-23.

141. Pan Y, Zhang Y, Liu W, Huang Y, Shen X, Jing R, et al. LncRNA H19 overexpression induces bortezomib resistance in multiple myeloma by targeting MCL-1 via miR-29b-3p. Cell Death Dis. 2019;10:106.

142. Yin D, Li Y, Fu C, Feng Y. Pro-angiogenic role of LncRNA HULC in microvascular endothelial cells via sequestrating miR124. Cell Physiol Biochem. 2018;50:2188-202.

143. Huang Y, Luo H, Li F, Yang Y, Ou G, Ye X, et al. LINC00152 down-regulated miR-193a-3p to enhance MCL1 expression and promote gastric cancer cells proliferation. Biosci Rep. 2018;38: BSR20171607.

144. Chen P, Fang X, Xia B, Zhao Y, Li Q, Wu X. Long noncoding RNA LINC00152 promotes cell proliferation through competitively binding endogenous miR-125b with MCL-1 by regulating mitochondrial apoptosis pathways in ovarian cancer. Cancer Med. 2018;7:4530-41.

145. Han Y, Wu N, Jiang M, Chu Y, Wang Z, Liu H, et al. Long noncoding RNA MYOSLID functions as a competing endogenous RNA to regulate MCL-1 expression by sponging miR-29c-3p in gastric cancer. Cell Prolif. 2019;52:e12678.

146. Li X, Yu M, Chen L, Sun T, Wang H, Zhao L, et al. LncRNA PMS2L2 protects ATDC5 chondrocytes against lipopolysaccharideinduced inflammatory injury by sponging miR-203. Life Sci. 2019; 217:283-92.

147. Zhou B, Li L, Li Y, Sun H, Zeng C. Long noncoding RNA SNHG12 mediates doxorubicin resistance of osteosarcoma via miR-320a/MCL1 axis. Biomed Pharmacother. 2018;106: $850-7$.

148. $\mathrm{Du} \mathrm{Q}, \mathrm{Hu} \mathrm{B}$, Feng Y, Wang Z, Wang X, Zhu D, et al. circOMA1-mediated miR-145-5p suppresses tumor growth of nonfunctioning pituitary adenomas by targeting TPT1. J Clin Endocrinol Metab. 2019;104:2419-34.

149. Wu Q, Yang F, Yang Z, Fang Z, Fu W, Chen W, et al. Long noncoding RNA PVT1 inhibits renal cancer cell apoptosis by upregulating Mcl-1. Oncotarget. 2017;8:101865-75.

150. Zheng X-L, Zhang Y-Y, Lv W-G. Long noncoding RNA ITGB1 promotes migration and invasion of clear cell renal cell carcinoma by downregulating Mcl-1. Eur Rev Med Pharm Sci. 2019;23:1996-2002. 